\title{
Relation to Sociodemographic Factors and Habits with Dental Anxiety, Dental Fear, and Quality of Life among Students of Different Faculties
}

\author{
Türkan S Erhamza ${ }^{1}$, Kubra A Carpar ${ }^{2}$
}

\begin{abstract}
Aim and objective: The study aimed to compare the dental fear, dental anxiety, and oral health-related quality of life of students of the faculty of dentistry, medical faculty, and other faculties and to examine the relationship between these variables and the demographic data and habits of individuals.

Materials and methods: The study involving 1,230 (725 females, 505 males) students from Faculty of Dentistry $(n=439)$, medicine $(n=498)$, and other faculties $(n=293)$ studying at Kırıkkale University. Individuals have applied a questionnaire consisting of questions on oral hygiene habits, dentist visits, smoking and alcohol use in the first part and Dental Fear Scale (DFS), Modified Dental Anxiety Scale (MDAS), and Oral Health Impact Profile (OHIP-14) in the second part.

Results: Dental fear scale, MDAS, and OHIP-14 scores showed a statistically significant difference between faculties $(p<0.05)$. The difference between medical students and other faculty students was not significant. Modified Dental Anxiety Scale scores were found to be significantly higher in females than in males $(p=0.005)$. There was no significant difference in MDAS, DFS, and OHIP-14 between different education years in medicine and other faculties.

Conclusions: Dental anxiety, fear levels of dentistry students were lower than other students of other faculties and their quality of life was higher. Dentistry education and the year of education have been found to have a potential impact on the dental anxiety, fear, and quality of life of the individuals.
\end{abstract}

Keywords: Dental anxiety, Dental fear, Dentistry students, Medicine students, Oral health-related quality of life.

Journal of Contemporary Dentistry (2020): 10.5005/jp-journals-10031-1277

\section{INTRODUCTION}

Fear and anxiety related to dental treatments are common despite novel advances providing better pain relief and improved patient comfort. ${ }^{1}$ Whereas the word fear itself is defined as a response to an identifiable, external threat, and anxiety as a response to a threat from an unknown cause or a response stemming from internal conflict, dental fear, and dental anxiety are interchangeable concepts. ${ }^{2,3}$

Dental anxiety and fear is an intense state of discomfort occurring due to the fear and delusions related to the treatment to be done during a dental visit with the purpose of treatment. ${ }^{2,3}$ Level of anxiety is generally affected by previous traumatic dental procedures, misdirection from the family and the environment, personal characteristics, age, gender, and educational status. ${ }^{2,4}$ Fear and anxiety are among the challenges to overcome in dentistry ${ }^{5,6}$ and big problems that can hinder treatment for several people. ${ }^{7}$ Individuals with high dental anxiety have a higher number of tooth loss, caries, and worse periodontal health than individuals with low dental anxiety. ${ }^{8-10}$

Quality of life is related to the physical condition, social relationships, and psychological state of the individual. Furthermore, expectations, living conditions, education level, and socioeconomic status of the individuals might be other influencers. Thus, evaluation of the quality of life is quite challenging. ${ }^{11}$ The oral health-related quality of life, on the other hand, determines the extent to which the experience and discomfort related to oral and dental health affecting the well-being of the individual. ${ }^{12}$ Individuals with high
1,2Department of Orthodontics, Faculty of Dentistry, Kırıkkale University, Kırıkkale, Turkey

Corresponding Author: Türkan $\mathrm{S}$ Erhamza, Department of Orthodontics, Faculty of Dentistry, Kırıkkale University, Kırıkkale, Turkey, Phone: +903182244927, e-mail: dt.turkansezen@gmail.com

How to cite this article: Erhamza TS, Carpar KA. Relation to Sociodemographic Factors and Habits with Dental Anxiety, Dental Fear, and Quality of Life among Students of Different Faculties. J Contemp Dent 2020;10(1):18-24.

Source of support: Nil

Conflict of interest: None

dental anxiety have many dental problems as they avoid dental treatment. ${ }^{8-10}$ Untreated dental problems become more severe over time and adversely affect the oral quality of life. ${ }^{13}$

In this study, (1) comparison of dental fear, dental anxiety, and quality of life of students from the faculty of dentistry, medicine, and other fields (Engineering, Arts and Sciences, Law, Education, and Economics and Administrative Sciences) and (2) evaluation of dental fear, dental anxiety, and quality of life among different grades in these faculties; (3) investigation of the relationship between demographic data and habits of the individuals and dental fear, dental anxiety, and quality of life; and (4) examination of the correlation between dental fear, dental anxiety, and quality of life, and (5) identifying the difference between genders were aimed. The null hypothesis of our study was there is no difference in terms 
of dental fear, dental anxiety, and quality of life among students of different faculties.

\section{Materials and Methods}

Our study is an epidemiological descriptive study with a population composed of students studying in various faculties of Kırıkkale University in 2018-2019. Ethics committee approval was obtained from the Kırıkkale University Non-Invasive Research Ethics Committee (Date: 16.01.2019, Decision No: 2019.01.11). Besides, approval and voluntary informed consent forms were collected from relevant faculty diocanates and from all the students who participated in the research, respectively, to perform the study.

Individuals with any psychological disorder and using drugs due to such disorder, alcohol and substance addiction, significant cognitive impairments, any neurological disease, or any mental problems were not included in the study. Of the individuals to whom the scales have been applied, 19 were excluded from the study because of psychological discomfort, and 37 due to the missing answers.

A total of 1,230 (725 females, 505 males) students with an average age of $21.16 \pm 1.97$ and ages ranging between 17 and 35 years from the Kırıkkale University Faculty of Dentistry $(n=439)$, Faculty of Medicine ( $n=498$ ), and other faculties (Engineering, Arts and Sciences, Law, Education and attended the Faculty of Economics and Administrative Sciences) $(n=293)$ were attended in the present study. The students were informed about the questionnaire and asked to fill out the questionnaire forms.

The questionnaire form consisted of two parts. The first part included questions related to oral hygiene habits, dentist visits, smoking, and alcohol use (Table 1). The second part included the dental fear scale (DFS) ${ }^{14}$ and the modified dental anxiety scale (MDAS), ${ }^{15}$ where the dental fear and anxiety were evaluated, and the Oral Health Impact Profile (OHIP-14), ${ }^{16}$ with which oral healthassociated quality of life was evaluated.

Dental fear scale consisting of 20 questions was used to collect information about dental fear. ${ }^{17,18}$ Scores ranging from 1 to 5 were used to evaluate the answers (a: 1, b: 2, c: 3, d: 4, e: 5 points). Low anxiety was identified with scores below 40 points, moderate anxiety with $40-60$ points, high anxiety with $60-80$ points, and extreme anxiety with 80 points and above. ${ }^{19}$

The MDAS scale, consisting of 5 questions, was used to evaluate dental anxiety. ${ }^{15}$ There were five alternatives for each question varying between "I never worry" and "I worry too much". According to the alternatives, answers were evaluated with scores varying between 1 point and 5 points. The total score ranged from 5 to 25 . Individuals with a score of 19 and above were identified as high anxious. $^{15}$

The OHIP-14 scale consisting of 14 questions was used to evaluate the oral health-related quality of life. ${ }^{20}$ The test consisted of questions with 5 alternatives scored between 0 and 4 (never: 0 points, rarely: 1 point, sometimes: 2 points, often: 3 points, and always: 4 points) and total scores ranged from 0 to 56 . The quality of life was negatively affected as the score increased. ${ }^{16,20}$

Statistical analyses were performed with SPSS software (version 20; IBM, Armonk, NY, USA). Mean, standard deviation, median, minimum, and maximum values were presented in descriptive statistics for continuous data and percentage values in discrete data. The Shapiro-Wilk test was used to analyze the data for normal distribution. In the comparison of quantitative data between groups, $t$-test and one-way ANOVA tests were used for independent samples. In case of a significant difference, the post hoc Tukey HDS test was applied. A Chi-square test was used for the differences between categorical data. Statistical significance was considered as the $p$ value $<0.05$.

\section{Results}

As a result of the power analysis, the power of the study was found to be 0.85 with the affected area being 0.153 and alpha error 0.05 .

In the study, a total of 1,230 (725 females, 505 males) students with an average age of $21.16 \pm 1.97$ and ages ranging between 17 years and 35 years from the faculty of dentistry $(n=439)$, faculty of medicine $(n=498)$, and other faculties $(n=293)$ were included. The average age and gender distribution by faculties are presented in Table 1.

While the monthly income of the families of students in the faculty of dentistry and medicine was mostly 4,000 TL and above, it varied between 2,500 TL and 4,000 TL for students of other faculties, and that income level was lower than that of students of faculty of medicine and dentistry. The difference in the monthly income of the families of the students among faculties was statistically significant $(p=0.000)$ (Table 1). The monthly income level was observed not to be associated with MDAS, DFS, and OHIP-14 scores ( $p>0.05)$.

While $80 \%$ of the students were non-smokers, $44.9 \%$ of the nonsmokers were medical students. $45.6 \%$ of smokers were from other faculties. The alcohol use rate of students was $12.8 \%$, and $38.9 \%$ of students who use alcohol were from other faculties. There was a significant difference between the faculties in terms of cigarette and alcohol use (Table 1). There was no relationship between smoking and alcohol use and MDAS, DFS, and OHIP-14 scores ( $p>0.05)$.

Of the participants, 13 had never visited a dentist. $40.5 \%$ of students having regular dentist visits were medical students. The regular dentist visits ratio was $57.6 \%$ among students from the faculty of dentistry, 30.3\% from the faculty of medicine, and $12.1 \%$ from other faculties. While most of the dentistry students have regular dentist visits, most of the students from the faculty of medicine and other faculties visit the dentist when they experience a dental problem, and this difference was found to be statistically significant (Table 1).

According to MDAS, 6.6\% (13 people) of individuals with high anxiety had regular dentist visits, $15.1 \%$ (97 people) reported having a dentist visit upon experiencing a dental problem $(p=0.000)$. According to DFS, $1 \%$ (2 people) of individuals with extremely high anxiety had regular dentist visits, $4.8 \%$ (31 people) declared to have a dentist visit upon experiencing a dental problem ( $p=$ 0.000 ). In addition, oral health-related quality of life was found to be $11.63 \pm 10.86$ for individuals having regular dentist visits, and $13.18 \pm 10.89$ for individuals having a dentist visit upon a problem. The oral health-related quality of life of individuals having regular dental controls was higher than those having a dentist visit upon a problem $(p=0.016)$.

A statistically significant difference was found among the grades in the faculty of dentistry in terms of the frequency of dentist visits $(p=0.000)$. Regular visits to the dentist were $4.4 \%$ for the first-, $11.4 \%$ for the second-, $10.5 \%$ for the third-, $29.8 \%$ for the fourth-, and $50 \%$ for the fifth-grade students.

When oral hygiene habits were evaluated, brushing teeth 2-3 times a day was high in all three groups. Of the students, $56.5 \%$ of using materials that contribute to oral hygiene such as dental floss and mouthwash were dentistry students. The vast majority of students in the medical faculty and other faculties 
Table 1: Evaluation of descriptive data by faculties

\begin{tabular}{|c|c|c|c|c|c|}
\hline & & Dentistry & Medicine & Other & $p^{*}$ \\
\hline Age & & $21.38 \pm 1.8$ & $21.08 \pm 2.19$ & $20.9 \pm 1.78$ & \\
\hline \multirow[t]{2}{*}{ Gender } & Female & 287 (39.6\%) & 283 (39.0\%) & 155 (21.4\%) & 0.002 \\
\hline & Male & 152 (30.1\%) & $215(40.5 \%)$ & $138(27.3 \%)$ & \\
\hline \multirow[t]{5}{*}{ Monthly income } & $1,000 \mathrm{TL}>$ & $16(28.1 \%)$ & 12 (21.1\%) & 29 (50.9\%) & 0.000 \\
\hline & $1,000-1,500 \mathrm{TL}$ & $23(31.9 \%)$ & $19(26.4 \%)$ & $30(41.7 \%)$ & \\
\hline & $1,500-2,500 \mathrm{TL}$ & $53(29.0 \%)$ & $63(34.4 \%)$ & 67 (36.6\%) & \\
\hline & $2,500-4,000 \mathrm{TL}$ & 135 (39.1\%) & $116(33.6 \%)$ & 94 (27.2\%) & \\
\hline & $4,000 \mathrm{TL}<$ & $212(37.0 \%)$ & $288(50.3 \%)$ & $74(23.8 \%)$ & \\
\hline \multirow[t]{3}{*}{ Cigarette use } & Not use & 358 (36.1\%) & 445 (44.9\%) & 188 (19\%) & 0.000 \\
\hline & Use & 64 (33.2\%) & 41 (21.2\%) & $88(45.6 \%)$ & \\
\hline & Quit & $17(37.0 \%)$ & $12(26.1 \%)$ & 17 (37.0\%) & \\
\hline \multirow[t]{2}{*}{ Alcohol use } & Not use & 385 (35.9\%) & $456(42.5 \%)$ & $232(21.6 \%)$ & 0.000 \\
\hline & Use & 54 (34.4\%) & 42 (26.8\%) & 61 (38.9\%) & \\
\hline \multirow[t]{2}{*}{ Dentist visits } & Not visits & $6(46.2 \%)$ & $5(38.5 \%)$ & $2(15.4 \%)$ & 0.667 \\
\hline & Visit & 433 (35.6\%) & 493 (40.5\%) & 291 (23.8\%) & \\
\hline \multirow[t]{3}{*}{ Frequency of dentist visits } & Regularly & $114(57.6 \%)$ & $60(30.3 \%)$ & $24(12.1 \%)$ & 0.000 \\
\hline & Occasionally & $185(47.7 \%)$ & $125(32.2 \%)$ & $78(20.1 \%)$ & \\
\hline & Having problem & $140(21.7 \%)$ & $313(48.6 \%)$ & $191(29.7 \%)$ & \\
\hline \multirow[t]{5}{*}{ Frequency of toothbrushing } & Once a day & $51(24.1 \%)$ & $81(38.2 \%)$ & $80(37.7 \%)$ & 0.000 \\
\hline & Two or three times a day & $365(38.8 \%)$ & $392(41.7 \%)$ & $184(19.6 \%)$ & \\
\hline & Three times a day more & $11(36.7 \%)$ & $9(30.0 \%)$ & $10(33.3 \%)$ & \\
\hline & Once a week & $8(34.8 \%)$ & $6(26.1 \%)$ & $9(39.1 \%)$ & \\
\hline & Come to mind & $4(16.7 \%)$ & $10(41.7 \%)$ & $10(41.7 \%)$ & \\
\hline \multirow[t]{2}{*}{ Hygiene tool use } & Use & $309(56.5 \%)$ & $132(24.1 \%)$ & $106(19.4 \%)$ & 0.000 \\
\hline & Not use & $130(19.0 \%)$ & $366(53.6 \%)$ & $187(27.4 \%)$ & \\
\hline \multirow[t]{5}{*}{ The subject evaluation of oral health } & Perfect & $29(22.0 \%)$ & $74(56.1 \%)$ & $29(22.0 \%)$ & 0.000 \\
\hline & Very good & $135(40.5 \%)$ & $141(42.3 \%)$ & $57(17.1 \%)$ & \\
\hline & Good & $207(41.6 \%)$ & $157(31.6 \%)$ & $133(26.8 \%)$ & \\
\hline & Not bad & $61(26.2 \%)$ & $112(48.1 \%)$ & $60(25.8 \%)$ & \\
\hline & Bad & $7(20 \%)$ & $14(40 \%)$ & $14(40 \%)$ & \\
\hline \multirow[t]{5}{*}{ Effect of oral and surrounding tissues on life } & None & $44(23.2 \%)$ & $98(51.6 \%)$ & $48(25.3 \%)$ & 0.000 \\
\hline & Too little & $78(42.2 \%)$ & $71(38.4 \%)$ & $36(19.5 \%)$ & \\
\hline & A little & $118(32.4 \%)$ & $159(43.7 \%)$ & $87(23.9 \%)$ & \\
\hline & Much & $144(41.4 \%)$ & $125(35.9 \%)$ & $79(22.7 \%)$ & \\
\hline & Too much & $55(38.5 \%)$ & $45(31.5 \%)$ & $43(30.1 \%)$ & \\
\hline
\end{tabular}

${ }^{*}$ Chi-square test

did not use auxiliary hygiene tools. The use of auxiliary hygiene tools showed a significant difference among groups $(p<0.05)$ (Table 1).

Among dentistry students, $10 \%$ of those using auxiliary hygiene tools were first-, $29.8 \%$ fourth-, and $24.9 \%$ fifth-grade students. The rate of use of auxiliary hygiene tools among the faculty of dentistry was statistically significantly higher for the fourth- and fifth-grade students compared to the first-grade students $(p<0.05)$.

According to MDAS, $6.6 \%$ (36 people) of individuals with high anxiety used oral hygiene tools, while $14.8 \%$ (101 people) not ( $p$ $=0.000$ ). Dental fear scale evaluation showed, $1.8 \%$ (10 people) of individuals with extremely high anxiety used oral hygiene tools, while $5 \%$ (34 people) not $(p=0.000)$. While the oral healthassociated quality of life was $11.17 \pm 9.85$ for patients using hygiene tools, it was $13.31 \pm 11.13$ for non-users. Individuals using hygiene tools were found to have a better oral health-associated quality of life $(p=0.000)$.

In the subjective evaluation of oral health, the highest score was "good" and the lowest score was "bad" for all three groups. $41.6 \%$ (207 people) of those who had good oral health were from the faculty of dentistry. While the condition of the mouth and surrounding tissues affected the life of the majority of the students from the faculty of dentistry "more", it affected the life of the majority of the students from medicine and other faculties "slightly". 38.5\% of those who had been highly affected were students from the faculty of dentistry (Table 1). While the OHIP-14 score of those who considered oral health very well in the subjective evaluation of oral health was $10.78 \pm 9.27$, the relevant score for those who considered oral health bad was $17.54 \pm 13.85$. The subjective evaluation revealed that individuals who thought 
to have well oral health had a higher oral health-related quality of life $(p=0.000)$.

The quality of life score of students who answered the question "How much does oral health affect your life?" as "none" was $9.39 \pm$ 9.82 , whereas it was $14.11 \pm 11.73$ for those who answered as "too much". The quality of life of those who had a great influence on oral health on life was found to be lower $(p=0.000)$.

Dental fear scale scores of all students attended in the study ranged between 19 and 97, and 53.1\% had low anxiety, 32.1\% moderate anxiety, $11.2 \%$ high anxiety, 3.6\% had extremely high anxiety. Modified dental anxiety scale scores ranged from 0 to 25, with low anxiety in $88.9 \%$ and high anxiety in $11.1 \%$.

The average DFS value was $41.86 \pm 11.38$ for all students. The corresponding value was $35.25 \pm 12.72$ for the students from faculty of dentistry, $45.05 \pm 18.62$ faculty of medicine, and $46.34 \pm 17.91$ other faculties (Fig. 1). A statistically significant difference was found between the faculty of dentistry and medicine and other faculties $(p=0.000)$; however, no significant difference was found between the faculty of medicine and other faculties ( $p=0.539$ ) (Table 2).

The mean MDAS value was $11.63 \pm 4.95$ for all students. The corresponding value was $9.87 \pm 3.74$ for students from faculty of dentistry, $12.85 \pm 5.38$ faculty of medicine, $12.20 \pm 4.95$ other faculties. A significant difference was found between the faculty of dentistry and medicine and other faculties $(p=0.000)$. There was no significant difference between the faculty of medicine and other faculties ( $p=0.152$ ) (Table 2 ).

The mean OHIP-14 score was $12.36 \pm 10.63$ for all students. Corresponding value was $9.19 \pm 8.91$ for the faculty of dentistry,

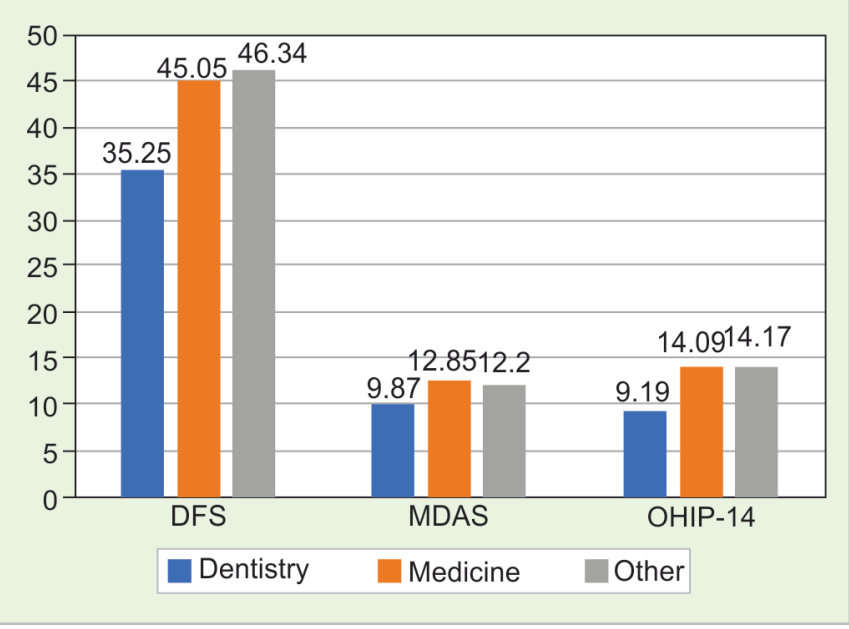

Fig. 1: DFS, MDAS, and OHIP-14 scores by faculties
$14.09 \pm 10.96$ for the faculty of medicine, and $14.17 \pm 11.32$ for other faculties. The difference between dentistry and medicine and other faculties was found to be significant $(p=0.000)$. No significant difference was observed between the faculty of medicine and other faculties ( $p=0.994$ ) (Table 2 ).

The average DFS score of females was $42.65 \pm 17.35$ and 40.73 \pm 17.13 for males. The difference between the scores of males and females was not statistically significant ( $p=0.056$ ) (Table 3 ).

The average MDAS score of females was $11.96 \pm 4.87$ and 11.16 \pm 5.02 for males. The average score of females was significantly higher than that of males ( $p=0.005$ ) (Table 3 ).

The average OHIP-14 score of females was $12.20 \pm 10.29$ and $12.59 \pm 11.10$ for males. There was no significant difference in terms of OHIP-14 scores of males and females ( $p=0.526$ ) (Table 3 ).

No significant difference was found for DFS, MDAS, and OHIP-14 scores of dentistry and medical students according to gender. A significant relationship was identified between MDAS and DFS scores of males and females in other faculty students $(p=0.000)$.

No significant difference was found in MDAS $(p=0.095)$, DFS ( $p$ $=0.095)$, and OHIP-14 scores ( $p=0.462$ ) among the grades of faculty of medicine. Similarly, no significant relationship was observed for MDAS $(p=0.952)$, DFS $(p=0.278)$, and OHIP-14 ( $p=0.576)$ scores among the grades of other faculties.

A significant difference was found between the MDAS, DFS, and OHIP-14 scores among the grades of faculty of dentistry. The average MDAS score for the first grades was $10.97 \pm 4.40,10.61 \pm$ 4.27 for the third grades, and $8.93 \pm 2.98$ for the fifth grades. The MDAS score of the fifth grades was significantly lower than the first grades $(p=0.04)$ and third grades $(p=0.027)$.

Dental fear scale scores were $39.35 \pm 15.28$ for the first grade, $37.73 \pm 13.49$ for the third grade, $33.72 \pm 12.30$ for the fourth grade, and $31.58 \pm 9.91$ for the fifth-grade students. A significant difference was found between the first and the fourth $(p=0.022)$ and the fifthgrade students $(p=0.01)$. Additionally, a significant difference was also noticed between the third and fifth-grade students $(p=0.013)$.

Oral health impact profile scores were inversely proportional to the education year. The average score was $12.71 \pm 9.87$ for the first-grade, $8.73 \pm 8.32$ for the third-grade, $9.00 \pm 8.50$ for the fourthgrade and $6.76 \pm 8.42$ for the fifth-grade students. The difference between the first-grade and the third-grade $(p=0.044 ; p<0.05)$, the fourth-grade $(p=0.038)$, and the fifth grade $(p=0.000)$ students were statistically significant.

A statistically significant positive correlation was found between MDAS and DFS scores $(p=0.000 ; r=0.740)$, MDAS and OHIP-14 scores $(p=0.000 ; r=0.278)$, and DFS and OHIP-14 scores $(p=0.000 ; r=0.740)$.

Table 2: Average DFS, MDAS, and OHIP-14 scores by faculties

\begin{tabular}{|c|c|c|c|c|c|c|c|}
\hline & & $n$ & Mean & Standard Deviation & $p^{*}$ & Between groups & Tukey's HSD \\
\hline \multirow[t]{3}{*}{ DFS } & Dentistry (I) & 439 & 35.25 & 12.72 & 0.000 & I-II & 0.000 \\
\hline & Medicine (II) & 498 & 45.05 & 18.62 & & I-III & 0.000 \\
\hline & Other (III) & 293 & 46.34 & 17.91 & & II-III & 0.539 \\
\hline \multirow[t]{3}{*}{ MDAS } & Dentistry (I) & 439 & 9.87 & 3.74 & 0.000 & I-II & 0.000 \\
\hline & Medicine (II) & 498 & 12.85 & 5.38 & & I-III & 0.000 \\
\hline & Other (III) & 293 & 12.20 & 5.04 & & II-III & 0.152 \\
\hline \multirow[t]{3}{*}{ OHIP-14 } & Dentistry (I) & 439 & 9.19 & 8.91 & 0.000 & I-II & 0.000 \\
\hline & Medicine (II) & 498 & 14.09 & 10.96 & & I-III & 0.000 \\
\hline & Other (III) & 293 & 14.17 & 11.32 & & II-III & 0.994 \\
\hline
\end{tabular}

*One-way ANOVA test 
Dental Anxiety, Dental Fear, and Quality of Life

Table 3: Average DFS, MDAS, and OHIP-14 scores by gender

\begin{tabular}{llllll}
\hline & Gender & $n$ & Mean & Standard deviation & $p^{*}$ \\
\hline DFS & Female & 725 & 42.65 & 17.35 & 0.056 \\
\multirow{2}{*}{ MDAS } & Male & 505 & 40.73 & 17.13 & 0.005 \\
& Female & 725 & 11.96 & 4.87 & 5.02 \\
\\
OHIP-14 & Male & 505 & 11.16 & 10.29 & 0.526 \\
& Female & 725 & 12.20 & 11.10 & \\
\hline
\end{tabular}

*Student's $t$-test

\section{Discussion}

Dental anxiety and fear is a common condition causing problems and decreasing the quality of life for physicians and patients despite developing technological advances. ${ }^{18,21}$ The incidence of dental anxiety in the entire population ranges from 4 to $23.4 \% .^{22}$ For the Turkish population, this rate varies between 21.3 and $23.5 \% .^{14,23}$ The studies to be carried out on this issue are gaining importance due to high rates of incidence. In our study, the effects of gender, education field, education year, and other factors that may have an impact on dental anxiety, dental fear, and quality of life were investigated.

Dental anxiety is evaluated by various scales and questionnaires. Contemporarily used common scales in adults are Corah DAS, MDAS, and DFS. $14,15,18,23-26$

Dental fear scale is a scale developed by Kleinknecht et al. ${ }^{18}$ and used to determine the level of fear against various practices in dentistry. Firat et al. ${ }^{14}$ reported that DFS is valid and reliable in Turkey in a study conducted in 2006.

CDAS was developed by Corah in 1969 to determine the level of dental anxiety. ${ }^{24}$ Although it is a widely used scale, it does not contain an assessment for local anesthesia injection. MDAS was created by adding a question measuring the level of anxiety related to injection to CDAS, and it was reported to have high reliability and validity. ${ }^{25}$ In studies conducted in Turkey, the scale has also been reported to be valid and reliable. ${ }^{15,26}$

To evaluate the psychosocial effects of oral health and its effects on quality of life, the OHIP scale was developed. It is the most effective and subjective tool in the measurement of oral health. ${ }^{20} \mathrm{OHIP}$ scale has been translated into Turkish by Başol et al. ${ }^{16}$ In our study, we used the DFS, MDAS, and OHIP-14 scales for which reliability and validity were demonstrated by several studies.

The high level of dental anxiety and fear is directly related to the decrease in quality of life. Dental anxiety has been reported to cause dental treatment avoidance and attitude of postponing treatment appointments. ${ }^{4}$ This situation results in the worsening of existing health problems. Therefore, individuals with high levels of dental anxiety and fear have a high number of caries and missing teeth. ${ }^{8,9}$ Moreover, the periodontal health of these individuals is poor. ${ }^{10}$ They have more complaints such as pain and discomfort affecting social life and psychological state. Hence, the quality of life decreases. In a study conducted in Switzerland, the relationship between dental anxiety and oral health-associated quality of life was investigated and high dental anxiety was reported to have a negative effect on the quality of life. ${ }^{21}$ In our study, a positive correlation was found between dental anxiety, fear, and oral health-related quality of life.

In some studies investigating dental anxiety and dental fear, females were found to have higher anxiety levels than males. ${ }^{21,27,28}$ On the other hand, no significant difference in terms of gender was reported by various authors. ${ }^{29}$ Females can express their feelings more comfortably than males. ${ }^{19}$ For this reason, higher scores of females may not imply higher fear and anxiety levels. In our study, whereas no significant difference was found in DFS scores between genders; the female gender was significantly associated with higher MDAS. No gender-associated difference was found in a vast majority of studies investigating the oral health-related quality of life. ${ }^{30}$ In our study, no significant relationship was found between the genders.

In the literature, studies investigating the relationship between the education year and dental anxiety exist. Acharya ${ }^{31}$ reported the faculty of dentistry students in the first years of education to have higher levels of anxiety. Ergüven et al. ${ }^{32}$ compared the senior year students of the faculty of dentistry with first-grade students and found the anxiety level of the first grades to be significantly higher. Peretz and Mann, ${ }^{33}$ similar to other studies, reported anxiety levels to decrease in the later years of education. In some of the studies on quality of life, the year of education has been reported to have a positive relationship with the quality of life. ${ }^{34}$ Acharya ${ }^{35}$ has found first-grade students of the faculty of dentistry to have higher OHIP-14 scores when compared to fourth-grade students; however, no statistically significant difference was found. Similar results were found in the study of Gonzales-Sullcahuamán et al. ${ }^{30}$ on students of the faculty of dentistry in Brazil. In our study, DFS, MDAS, and OHIP-14 scores of the first-grade students of the faculty of dentistry were found to be significantly higher than the fifth-grade students. No significant difference was found among the grades of faculty of medicine and the grades of other faculties. Considering these findings, we suggest a higher level of knowledge and experience about dentistry results in lower anxiety and fear and a better quality of life.

In the studies evaluating the relationship between the field of education and dental anxiety, the students of the faculty of dentistry were found to have a lower level of anxiety compared to the students of faculty of medicine and engineering; however, this difference was not statistically significant. ${ }^{36}$ In our study, the level of dental anxiety, fear, and quality of life were investigated in students of faculty of dentistry, medicine, and other faculties (Engineering, Arts and Sciences, Law, Education, and Economics and Administrative Sciences), and MDAS, DFS, and OHIP-14 scores were significantly lower in dentistry faculty students. Thus, our null hypothesis has been rejected. This result supports the increase in education and experience about dentistry to have an impact on dental fear, anxiety, and quality of life.

Those with high dental anxiety tend to find excuses and postpone appointments in order not to go to the dentist. Those who regularly visit dentists have lower dental anxiety levels than those having dentist visits upon a problem. ${ }^{37-39}$ The quality of life decreases as the number of periodontal diseases or missing teeth 
increases. A regular visit to the dentist ensures early detection of discomfort, preventing possible missing tooth. That is why regular dentist visit means a better quality of life. ${ }^{30}$ In our study, the fact that the students of the faculty of dentistry go to the dentist regularly compared to those of the faculty of medicine and other faculty supports that dental fear, anxiety, and quality of life scores are significantly lower among students of dentistry than other faculties. In addition, the rate of regular visits to the dentist, which increases as the grade progresses in the faculty of dentistry, decreases the level of dental fear, anxiety, and the quality of life increases with the education year. A high level of clinical experience, as well as knowledge of dentistry, maybe a reason for lower fear and anxiety scores.

Most of the students who think to have well oral hygiene in the subjective evaluation of oral health are the students of the faculty of dentistry. The high quality of life of those who have good oral hygiene supports that the quality of life of dentistry faculty students is higher than that of medical and other faculty students.

In our study, the majority of those who use oral hygiene aids are dentistry students. The vast majority of students in the faculty of medicine and other faculties do not use auxiliary hygiene tools. The rate of use of auxiliary hygiene tools in the faculty of dentistry increases in the fourth and fifth grades compared to the first grade. Tooth brushing habit also increases as the education year increases. This situation may be related to awareness of possible diseases and increased awareness about oral and dental health. People with good oral hygiene also have a high quality of life as they have relatively good oral health. ${ }^{30}$ In our study, the quality of life of those who use auxiliary hygiene tools was found to be higher in supporting this information.

\section{Conclusion}

- Fear and anxiety levels of the students of the faculty of dentistry were found to be significantly lower with a significantly better quality of life than that of the medical and other faculty students.

- Dental anxiety was significantly higher in females than in males, no difference was found in dental fear and quality of life.

- As the education year of dentistry faculty increases, the level of fear and anxiety decreases, and their quality of life increases.

- No significant relationship was found between MDAS, DFS, and OHIP-14 scores between different education years of medical and other faculty students.

- A relationship between dentist visits, brushing teeth, using auxiliary oral hygiene tools, and dental fear, anxiety, and quality of life was found.

- Modified Dental Anxiety Scale, DFS, and OHIP-14 scales showed a positive relationship with each other.

\section{References}

1. Freeman R. Barriers to accessing and accepting dental care. Br Dent J 1999;187(2):81-84. DOI: 10.1038/sj.bdj.4800208.

2. Ragnarsson B, Arnlaugsson S, Karlsson KÖ. Dental anxiety in Iceland: an epidemiological postal survey. Acta Odontol Scand 2003;61(5):283-288. DOI: 10.1080/00016350310005844.

3. Weiner AA. The fearful dental patient: A guide to understanding and managing; John Wiley \& Sons. 1st ed. Blackwell; 2011. pp. 16-35.

4. Schuller AA, Willumsen T, Holst D. Are there differences in oral health and oral health behavior between individuals with high and low dental fear? Community Dentis Oral Epidemiol 2003;31(2):116-121. DOI: 10.1034/j.1600-0528.2003.00026.x.

5. Hakeberg M, Berggren U, Carlsson SG. Prevalence of dental anxiety in an adult population in a major urban area in Sweden. Community Dentis Oral Epidemiol 1992;20(2):97-101. DOI: 10.1111/j.16000528.1992.tb00686.x.

6. Teo CS, Foong W, Lui HH, et al. Prevalence of dental fear in young adult Singaporeans. Int Dent J 1990;40(1):37-42.

7. Chadwick BL. Assessing the anxious patient. Dent Update 2002;29(9):448-454. DOI: 10.12968/denu.2002.29.9.448.

8. Carson P, Freeman R. Dental caries, age and anxiety: factors influencing sedation choice for children attending for emergency dental care. Community Dentis Oral Epidemiol 2001;29(1):30-36. DOI: 10.1034/j.1600-0528.2001.00006.x.

9. Hakeberg M, Berggren U, Gröndahl HG. A radiographic study of dental health in adult patients with dental anxiety. Community Dentis Oral Epidemiol 1993;21(1):27-30. DOI: 10.1111/j.1600-0528.1993. tb00714.x.

10. Locker D, Liddell A. Clinical correlates of dental anxiety among older adults. Community Dentis Oral Epidemiol 1992;20(6):372-375. DOI: 10.1111/j.1600-0528.1992.tb00702.x.

11. Allison PJ, Locker D, Feine JS. Quality of life: a dynamic construct. Soc Sci Med 1997;45(2):221-230. DOI: 10.1016/s0277-9536(96) 00339-5.

12. Inglehart MR, Bagramian RA, ed. Oral health-related quality of life: an introduction. In: Oral health-related quality of life. Chicago: Quintessence Publishing Co., Inc.; 2002. pp. 1-6.

13. Crofts-Barnes NP, Brough E, Wilson KE, et al. Anxiety and quality of life in phobic dental patients. J Dent Res 2010;89(3):302-306. DOI: $10.1177 / 0022034509360189$.

14. Firat $D$, Tunc E, Sar V. Dental anxiety among adults in Turkey. J Contemp Dent Pract 2006;7(3):75-82. DOI: 10.5005/jcdp-7-3-75.

15. Ilgüy $D$, llgüy $M$, Dinçer $S$, et al. Reliability and validity of the modified dental anxiety scale in Turkish patients. J Int Med Res 2005;33(2):252259. DOI: 10.1177/147323000503300214.

16. Başol ME, Karaağaçlioğlu L, Yilmaz B. Türkçe Ağız Sağlığı Etki Ölçeğinin Geliştirilmesi-OHIP-14-TR. Turkiye Klinikleri Dishekimligi Bilimleri Dergisi 2014;20(2):85-92.

17. Kleinknecht RA, Bernstein DA. The assessment of dental fear. Behav Ther 1978;9(4):626-634. DOI: 10.1016/S0005-7894(78)80138-5.

18. Kleinknecht RA, Klepac RK, Alexander LD. Origins and characteristics of fear of dentistry. J Am Dent Associat 1973;86(4):842-848. DOI: 10.14219/jada.archive.1973.0165.

19. Yildirim TT, Kaya FA, Uysal E. Diş Hekimi Korkusu ile Cinsiyet, Yaş, Medeni Durum, Diş Hekimine Gitme Sıklığı, Eğitim, Sosyo-Ekonomik ve Periodontal Durum Arasındaki İlişkinin İncelenmesi. Türkiye Klinikleri Diş Hekimliği Bilimleri Dergisi 2013;19(2):77-85.

20. Slade GD, Spencer AJ. Development and evaluation of the oral health impact profile. Community Dent Health 1994;11(1):3.

21. Gisler V, Bassetti R, Mericske-Stern R, et al. A cross-sectional analysis of the prevalence of dental anxiety and its relation to the oral healthrelated quality of life in patients with dental treatment needs at a university clinic in Switzerland. Gerodontology 2012;29(2):e290-e6. DOI: 10.1111/j.1741-2358.2011.00465.x.

22. Jaakkola $S$, Rautava $P$, Alanen $P$, et al. Dental fear: one single clinical question for measurement. Open Dentis J 2009;3(1):161. DOI: $10.2174 / 1874210600903010161$.

23. Armfield JM. How do we measure dental fear and what are we measuring anyway? Oral Health Prevent Dentis 2010;8(2):107-115.

24. Corah NL. Development of a dental anxiety scale. J Dent Res 1969;48(4):596. DOI: 10.1177/00220345690480041801.

25. Humphris GM, Morrison T, Lindsay S. The modified dental anxiety scale: validation and United Kingdom norms. Community Dent Health 1995;12(3):143-150.

26. Tunc EP, Firat $D$, Onur OD, et al. Reliability and validity of the modified dental anxiety scale (MDAS) in a Turkish population. Community 
Dentis Oral Epidemiol 2005;33(5):357-362. DOI: 10.1111/j.16000528.2005.00229.x.

27. Peretz B, Moshonov J. Dental anxiety among patients undergoing endodontic treatment. J Endodont 1998;24(6):435-437. DOI: 10.1016/ S0099-2399(98)80028-9.

28. Sghaireen MG, Zwiri A, Alzoubi IA, et al. Anxiety due to dental treatment and procedures among university students and its correlation with their gender and field of study. Int J Dentis 2013;2013:647436. DOI: 10.1155/2013/647436.

29. Thomson WM, Locker D, Poulton R. Incidence of dental anxiety in young adults in relation to dental treatment experience. Community Dentis Oral Epidemiol 2000;28(4):289-294. DOI: 10.1034/j.16000528.2000.280407.x.

30. Gonzales-Sullcahuamán JA, Ferreira FM, de Menezes JV, et al. Oral health-related quality of life among Brazilian dental students. Acta Odontológica Latinoamericana 2013;26(2):76-83.

31. Acharya S. Factors affecting dental anxiety and beliefs in an Indian population. J Oral Rehabil 2008;35(4):259-267. DOI: 10.1111/j.13652842.2007.01777.x.

32. Ergüven SS, Kılınç $Y$, Delilbaşı $E$, et al. Bir diş hekimliği fakültesi ağız, diş ve çene cerrahisi kliniğine başvuran hastaların dental kaygı düzeylerinin değerlendirilmesi. Acta Odontologica Turcica 2015;32(1):7-11. DOI: 10.17214/aot.65466.
33. Peretz B, Mann J. Dental anxiety among Israeli dental students: a 4-year longitudinal study. Eur J Dent Educat 2000;4(3):133-137. DOI: 10.1034/j.1600-0579.2000.040308.x.

34. Locker D, Slade G. Oral health and the quality of life among older adults: the oral health impact profile. J (Canadian Dental Association) 1993;59(10):830-833.

35. Acharya S, Sangam DK. Oral health-related quality of life and its relationship with health locus of control among Indian dental university students. Eur J Dent Educat 2008;12(4):208-212. DOI: 10.1111/j.1600-0579.2008.00519.x.

36. Al-Omari WM, Al-Omiri MK. Dental anxiety among university students and its correlation with their field of study. J Appl Oral Sci 2009;17(3):199-203. DOI: 10.1590/s1678-77572009000300013.

37. Hägglin $C$, Hakeberg $M$, Ahlqwist $M$, et al. Factors associated with dental anxiety and attendance in middle-aged and elderly women. Community Dentis Oral Epidemiol 2000;28(6):451-460. DOI: 10.1034/j.1600-0528.2000.028006451.x.

38. Maggirias J, Locker D. Five-year incidence of dental anxiety in an adult population. Community Dent Health 2002;19(3):173-179.

39. Moore R, Brødsgaard I, Mao TK, et al. Fear of injections and report of negative dentist behavior among Caucasian American and Taiwanese adults from dental school clinics. Community Dentis Oral Epidemiol 1996;24(4):292-295. DOI: 10.1111/j.1600-0528.1996.tb00862.x. 